\title{
Living foreign body: Leech inside the nasal cavity causing epistaxis
}

\author{
S Manandhar ${ }^{1}$, S Chettri ${ }^{1}$, S Shah ${ }^{1}$, BP Sah ${ }^{1}$, S Shilpakar ${ }^{1}$, S Mishra ${ }^{1}$, D Kandel ${ }^{1}$, PP Gupta ${ }^{2}$ \\ Department of Otorhinolaryngology and Head \& Neck Surgery ${ }^{1}$, Department of General Practice and \\ Emergency Medicine ${ }^{2}$, B.P. Koirala Institute of Health Sciences, Dharan, Nepal
}

\begin{abstract}
This is a case report of a three years old male child presented in the Otolaryngology and Head \& Neck Surgery with chief complain of bleeding from the left nostril since seven days with nasal itching which was later diagnosed to be living foreign body leech causing epistaxis.
\end{abstract}

Key words: Foreign body, leech, nose

\section{Introduction}

Foreign bodies in the nose are common in children as the children have habit of exploring things and putting things inside the nose, ear and mouth but discovering live leech inside the nose causing epistaxis is very rare and interesting. ${ }^{1}$ Leeches are blood sucking hermophroditic parasite having variation in color and length. They are cylindrical leafy in shape and length can be altered depending upon its contractility. They are slippery to touch. ${ }^{2}$

\section{A case report}

A 3-year-old male child resident of Dhankuta was brought by his grandfather in the Otolaryngology and Head and Neck Surgery OPD with chief complain of bleeding from left

\footnotetext{
Address for correspondence

Dr. Sriti Manandhar

Assistant Professor

Otolaryngology and Head and Neck Surgery.

B.P. Koirala Institute of Health Sciences, Dharan

E-mail: sriticha@gmail.com
}

side of the nose since seven days with nasal itching. Child was treated in primary health centre with antibiotics and nasal decongestant but the symptoms did not subside so was referred to BPKIHS. On anterior rhinoscopy blood mixed discharge was present. As the child was uncooperative, he was wrapped with bed sheet laid supine. Head was made stable and using nasal speculum blood was sucked.

On inspection using otoscope: blackish brownish mass was seen in left nasal cavity but could not remove in first two attempts, in third attempt with great effort it was grasp with an artery forcep and kept in a water filled kidney tray.

To our surprise a blackish brownish leech swimming in water filled kidney tray was found which was living in human body for seven days. 


\section{Discussion}

Leech manifestation is common in hilly areas of Nepal. Portal of entry is by drinking or swimming in water harboring leeches and gain access to the human body generally through nose and oral cavity. Removing living leech from the nasal cavity is a very difficult as it has a strong attachment to the nasal mucosa and its slippery body makes the task more difficult. ${ }^{2,3,4}$ It can deteriorate general condition of the patient as it can migrate to the nasopharynx, oropharynx and even gaining access to the airway (larynx, trachea, lungs) or esophagus causing epistaxis, haematemesis, hoarseness, respiratory distress. $^{2,5}$
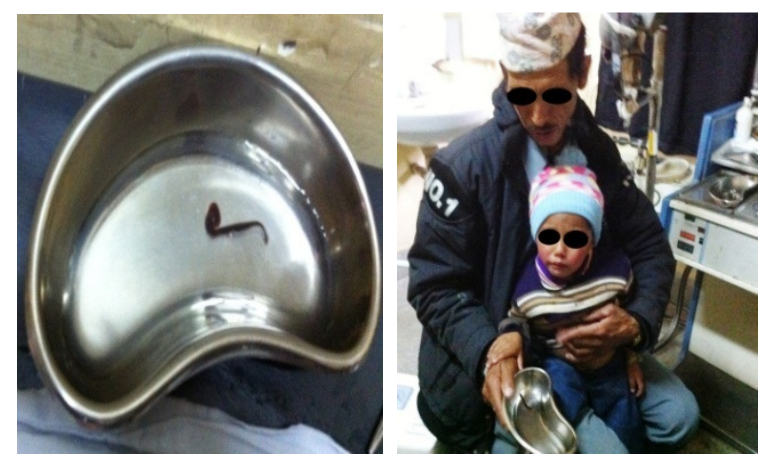

\section{Conclusion}

Hence leech as a foreign body nose should always be kept as a differential diagnosis especially in patients presenting with epistaxis and belong to leech manifested area. It could be fatal if it could not be diagnosed as the living foreign body can migrate to aerodigastric tract causing airway obstruction leading to respiratory distress.

\section{References}

1. Carney AS, Patel $\mathrm{N}$ and Clarke $\mathrm{R}$. Foreign bodies in the ear and aerodigestive tract in children. Otorhinolaryngology and Head and Neck Surgery.

Paediatric otorhinolaryngology. 2008; I, Part B, Part $12 ; \mathrm{p} 1186$.

2. Bhandary S, Regmi D, Joshi RR. Laryngeal leech. An unusual cause of hoarseness. Otolaryngology and Head \& Neck Surgery. 2010: 7;2

3. Adhikari P. Nasal Leech infestation in children. International Journal of Paediatric Otolaryngology.2009: 73; 853855.

4. Chow CK, Wong SS, Ho AC, Lau SK. Unilateral epistaxis after swimming in a stream , Hongkong Med. J. 2005: 11;110112

5. El-Award ME, Patil K. Haematemesis due to leech infestation. Ann Trop. Paediatr. 1990:10; p 61-62. 